\title{
OPEN Author Correction: Analog Coding in Emerging Memory Systems
}

\author{
Ryan V. Zarcone, Jesse H. Engel, S. Burc Eryilmaz, Weier Wan, SangBum Kim ${ }^{0}$, \\ Matthew BrightSky, Chung Lam, Hsiang-Lan Lung, Bruno A. Olshausen \& H.-S. Philip Wong
}

The Acknowledgements section in this Article is incomplete.

"This work was supported in part by SONIC, one of six centers of STARnet, a Semiconductor Research Corporation program sponsored by MARCO and DARPA, by member companies of the Stanford SystemX Alliance, and member companies of the Stanford Non-Volatile Memory Technology Research Initiative (NMTRI). R.Z. was supported by a National Science Foundation Graduate Research Fellowship under Grant No. DGE 1752814".

should read:

"This work was supported in part by SONIC, one of six centers of STARnet, a Semiconductor Research Corporation program sponsored by MARCO and DARPA, by member companies of the Stanford SystemX Alliance, member companies of the Stanford Non-Volatile Memory Technology Research Initiative (NMTRI), and a research gift from Intel Corporation. R.Z. was supported by a National Science Foundation Graduate Research Fellowship under Grant No. DGE 1752814".

\begin{abstract}
(c) Open Access This article is licensed under a Creative Commons Attribution 4.0 International License, which permits use, sharing, adaptation, distribution and reproduction in any medium or format, as long as you give appropriate credit to the original author(s) and the source, provide a link to the Creative Commons license, and indicate if changes were made. The images or other third party material in this article are included in the article's Creative Commons license, unless indicated otherwise in a credit line to the material. If material is not included in the article's Creative Commons license and your intended use is not permitted by statutory regulation or exceeds the permitted use, you will need to obtain permission directly from the copyright holder. To view a copy of this license, visit http://creativecommons.org/licenses/by/4.0/.
\end{abstract}

(C) The Author(s) 2020 